\title{
The birth of biometric security
}

\section{Mark Maguire}

Mark Maguire is a Lecturer in the Department of Anthropology, National University of Ireland,

Maynooth. He was the 2008 Fulbright Advanced Research Scholar in the Western Institute for Irish Studies, Stanford University, where he is also a Visiting Associate Professor in the Department of Anthropology. His email is Mark.H.Maguire@nuim.ie

Fig. 1. Three-dimensional Face Recognition Shown at a Biometrics Conference, London, 2004.
Fig. 2. Dutch national IDs require static 'mug-shots'so official identification matches face recognition scanners. In early 2007, Robert Coleman, at the time a security guard of 'Het Torentje' (the round tower which serves as the office for the Dutch prime minister in The Hague), managed to procure a Dutch national ID dressed as The Joker from Batman (claiming his attire was necessary for religious reasons), used it to fly to London and was photographed outside 10 Downing Street. Thus illustrating, at the very least. the human error potential in modern security systems.

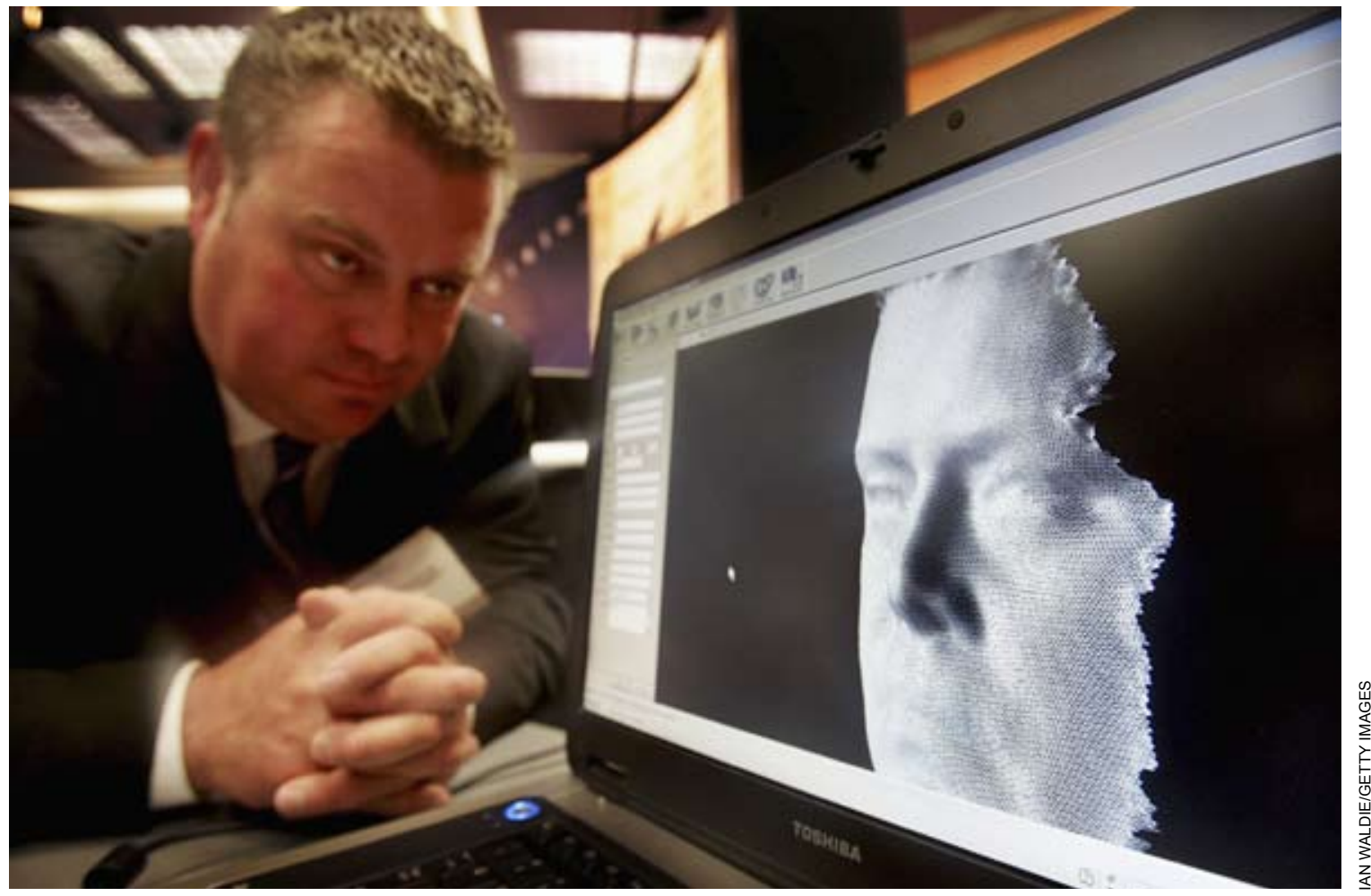

Imprisonment, having for its only object the detention of individuals, might become rare, when they were held as it were by an invisible chain. Jeremy Bentham

Biometrics, from the Ancient Greek bios and metron, denotes the recognizing of humans on the basis of intrinsic physical or behavioural traits. Biometric systems differ from more traditional forms of security by identifying the body alongside knowledge or possession tokens, such as passwords or documents. The common recognition characteristics are the face, fingerprint or iris. However, ongoing research is developing recognition of vascular pattern, hand geometry, DNA and even body odour. Behavioural biometrics encompasses handwriting, voice and keystroke patterns, together with growing fields such as gait recognition. Since the late 1990s there has been a revolution in biometrics for primary security access and, in some cases, as replacement technologies for older forms of identification.

Most people experience biometrics in an airport or restricted building. Here, it is sufficient to note that the process involves taking an image of characteristics and 'enrolling' it in a database, comparing it to stored data and running a performance system to test accuracy and filter noise, such as motion or light. Biometric security thus involves an information system with multiple levels of access, degrees of openness and potential for inaccuracies. Unsurprisingly, the technical literature is dominated by encryption, efforts to model efficacy and establish 'best practice' - and with good reason. In recent years, there have been a number of well-publicised debacles. In 2002, for example, a security industry conference in Las Vegas heard that researcher Tsutomu Matsumoto gained access to an unfamiliar bio- metric system in under 60 minutes using fake fingerprints moulded from Gummi Bear sweets. ${ }^{1}$ Other examples include recent erroneous imprisonment cases in the US due to 'false positives'.

Civil liberties organizations have been quick to point to the serious implications for privacy and the dangers of reliance on single biometric technologies, but this has done little to diminish investment in areas ranging from 'smart' borders and e-banking to benefit and welfare payments. Indeed, according to recent estimates, by 2010 the market for security solutions for European airports will reach 10 billon euros. And if we follow Naomi Klein, the future may well be cultivated in more distant 'laboratories', such as the Chinese port city and export zone of Shenzhen, where

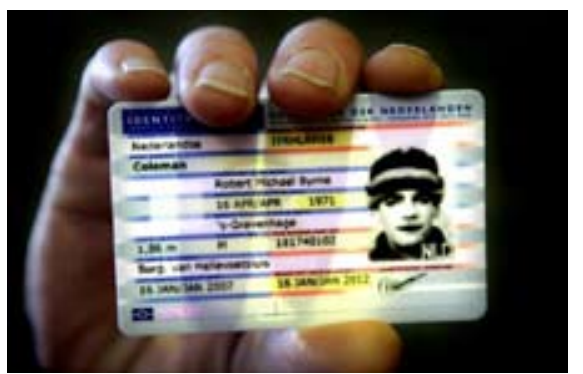
experimental bio-IDs store data on one's reproductive history and even landlords' phone numbers.

For some commentators, the current revolution in biometrics marks a new era of surveillance in which the body is both the target and the instrument of control. Speaking of 'smart' borders, David Lyon (2007) recently argued that citizenship becomes less significant in a world in which the body is the passport to spaces and privileges. The insights of Michel Foucault, particularly his work on panopticism, are central to surveillance studies, and there is a growing literature on the relationship between modern governmentality and what Nikolas Rose has termed the 'securitization of identity' (1999: 240).

Biometric security has received little anthropological attention despite historical associations with the discipline. This article represents elements of a larger project on technologies of mobility control, and here I wish to stake out a 
Fig. 3. 'Biometrics at War'. US soldier scans and Iraqi youth's iris using a biometrics digital system camera during an enlistment program session to join the Sahwa group in Mahmudiyah, some $30 \mathrm{kms}$ (18 miles) south of Baghdad, on May 5, 2008.

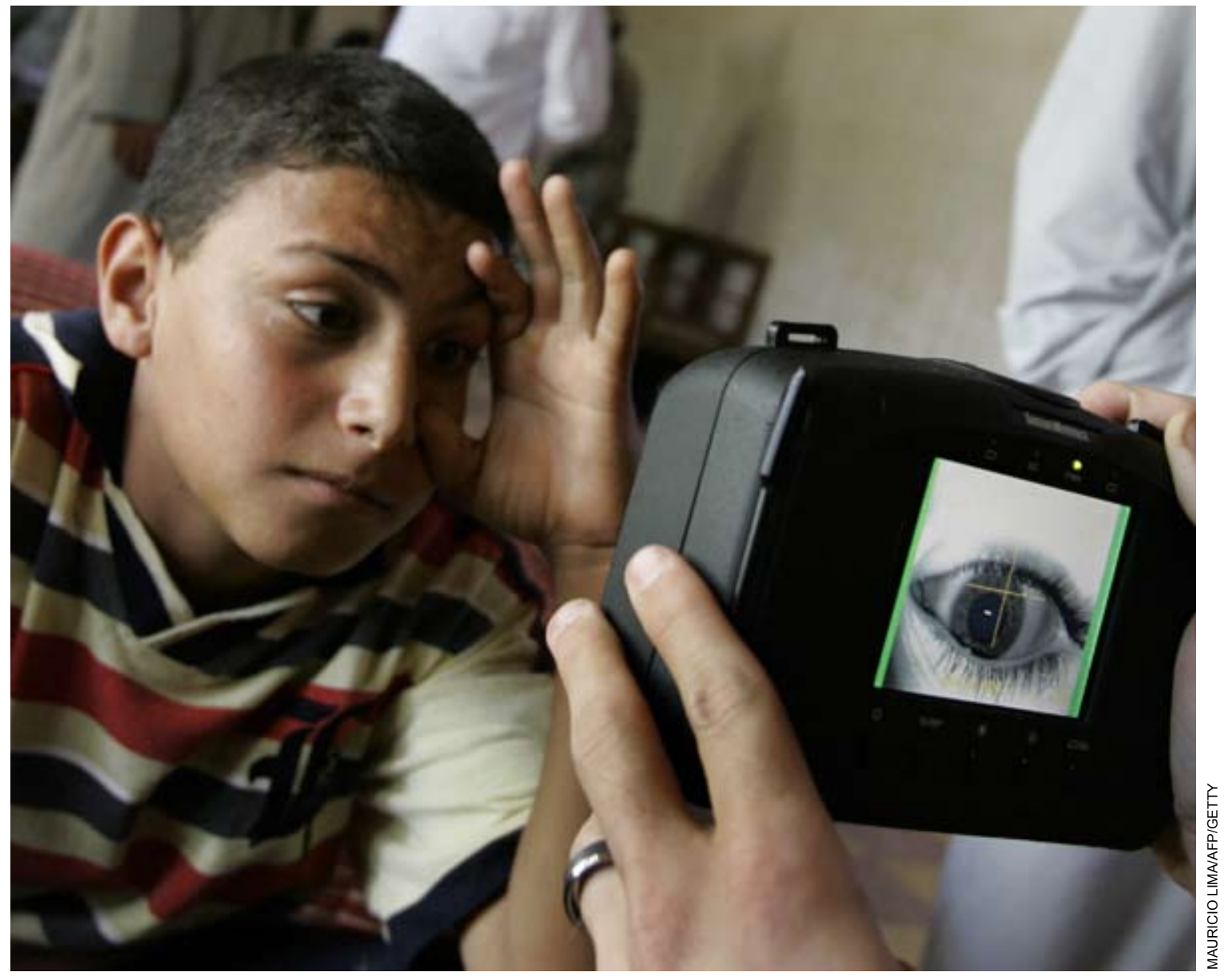

position in relation to this topic. However, my perspective will be informed by historical insights rather than ethnographic ones. Essentially, I am asking the question: what may be learned from a history of the present revolution in biometric security?

Use of biometrics can be identified in a variety of historical moments, from Assyrian payment receipts to inky footprints on ancient Chinese divorce records. However, biometric security, in the modern sense, was born in the 19th century, through the innovations of administrators, anthropologists and French detectives and in contexts as varied as colonial India, metropolitan London and finde-siècle Paris. Unsurprisingly, much has already been written about the emergence of police photography and fingerprinting as chapters within the history of criminology and forensics. Other biometric solutions such as anthropometry, once regarded as scientifically superior, now appear as historical curiosities. But the history of biometrics reveals more than simply periods of innovation, testing, and varied levels of legal and public acceptance. Fingerprinting and face recognition, which are at the heart of the contemporary revolution in biometrics (and my focus here), offered 19th-century innovators more than the prospect of criminal identification: early biometrics promised a utopia of bio-governmentality in which individual identity verification was at the heart of population control.

In the brief historical survey below I will argue that figures such as the colonial administrator William Herschel, the anthropologist and eugenicist Francis Galton and the detective Alphonse Bertillon did not simply 'discover' technologies of human identification, classification and data archiving; rather, each foresaw and spoke of the possibilities for systems of biometric security. Today, with exponential growth in imaging and processing technologies and the increasing drive towards the securitization of identity, the utopia of bio-governmentality evoked in the late 19 th century is finding new champions.
Fingerprints, photographs and filing cabinets

In 1880 the stirrings of a hundred-year-long controversy were to be found in the pages of the journal Nature. Henry Faulds, a Scottish medical missionary in Tokyo, published a short letter outlining his observations on fingerprints, from those of primates to human impressions on ancient pottery. Faulds noted that these 'nature-copies' could be compared visually, potentially leading to the 'scientific identification of criminals' (1880: 605). Soon after William Herschel, a former Assistant Joint Magistrate in India, wrote a followup article in Nature pointing out that he had been working with fingerprints for more than 20 years in a broader effort to verify the identities of colonial subjects. The 'discovery' controversy continues to this day; however, a considerable body of scholarship now argues that fingerprints may have been used to authenticate identity in a variety of cultures for many thousands of years (see Beavan 2002). Looking beyond the development of fingerprinting for criminal identification, the contribution of William Herschel is most remarkable as an early attempt to roll out biometric

Herschel traced the genesis of modern fingerprinting to his epiphanic encounter with 'native' signatures. In 1858 he was contracting road-building materials in India's Hooghly River region on behalf of the British administration (initially for the East India Company). He demanded that a local man, Rajyadhar Kōnāi, sign a contract supplemented by his palm print with the intention of 'frightening' him. Local use of palm prints and fingertips, tip sahi, in written agreements was not uncommon, but Herschel was struck by the power of these nature copies to be both reproducible and real. Colonial texts spoke of the obscurity that arose because individual identity was unfixed in the colonial gaze, and Herschel saw biometrics as the practical solution. Later, as Magistrate for Hooghly, he used fingerprinting to combat fraud in pension claims, where it was rumoured that one could hire an elderly 'relative'; security in a variety of civil areas. 
Fig. 3. 'The Jewish Type' Example of composite portraiture from Life of Francis Galton by Karl Pearson Vol 2 : image 0341

1. Disturbingly, in 2007, German Interior Minister Wolfgang Schäuble's fingerprints were copied from a drinking glass at a university reception by members of the Chaos Computer Club and an image published in a magazine with instructions on how it could be used to deceive security systems.

2. The 'discovery' controversy also involved Galton. Prior to the letter in Nature, Henry Faulds wrote to Charles Darwin hoping for his assistance. Darwin forwarded the letter to Francis Galton, who did not reply to Faulds, but forwarded the letter to the Royal Anthropological Society where it received no attention and was returned to Galton in 1894. By

the early 1880 s scientific journals had moved on to other matters, and Faulds decided to write to police chiefs around the world to campaign for fingerprinting. He received few replies, as many police forces had become enraptured by anthropometry.

3. Biometrics such as fingerprints are normally used with respect to populations composed of enrolled individuals, e.g. a criminal database. The uses of biometrics comprise authentication, which involves matching within acceptable error levels the biometrics presented with specific stored information, and identification, where the data is compared to all data within the sample.

Since the Indian Evidence Act of 1899, the world's first legal endorsement of fingerprinting as a criterion of identification, an image of fingerprinting as the most

Fig. 5. 'Mensuration de la coudée' From Alphonse Bertillon's exhibition at the 1893 World's Columbian Exposition in Chicago.

Permission required from the National Gallery of Canada Ottawa.

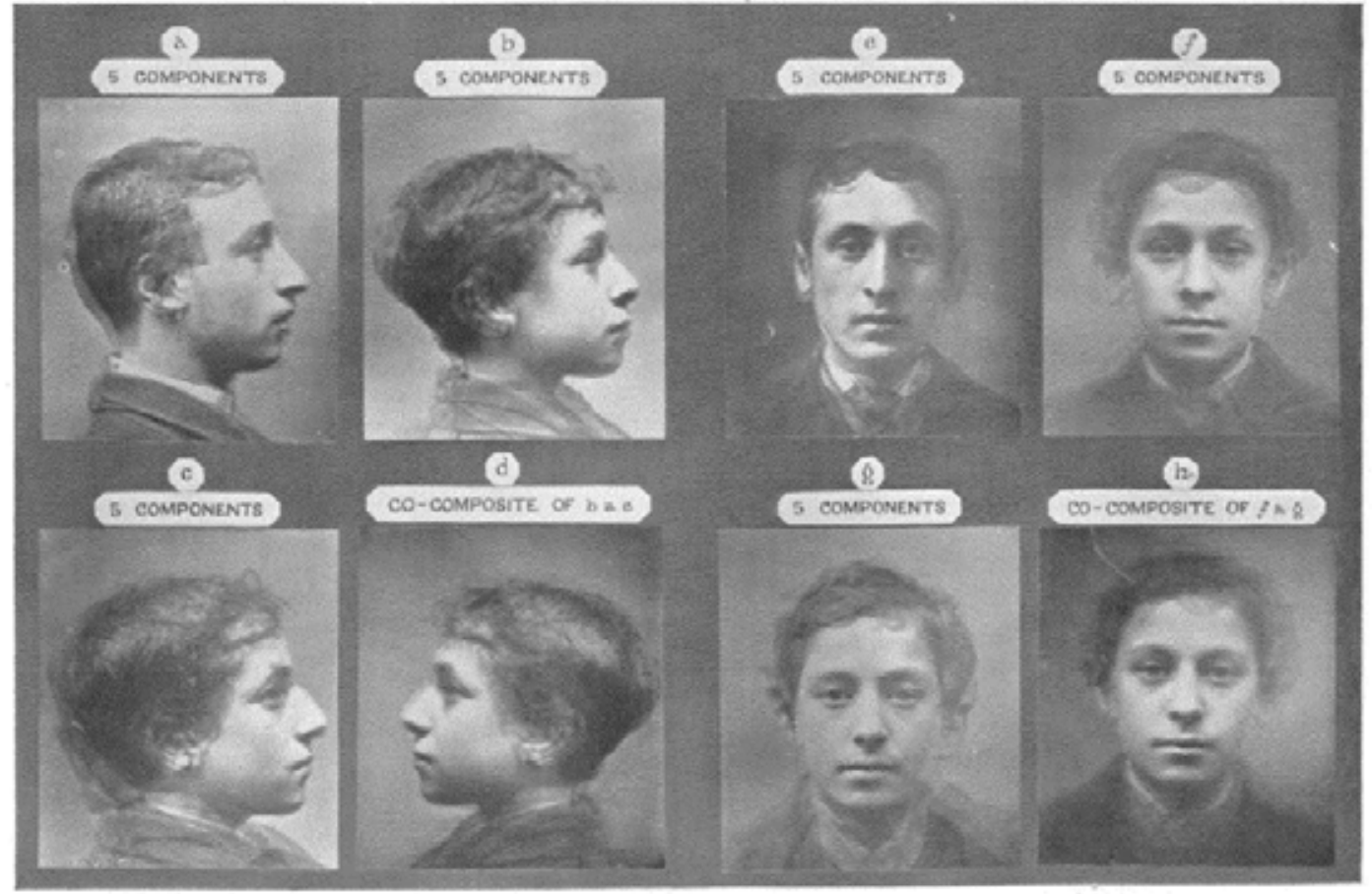

$$
\text { Profle. }
$$

apparently prisoners were also available to serve one's sentence.

In Mimesis and alterity, Michael Taussig refers to the work of Herschel as the 'organized control of mimesis', a modernist sorcery through which the copy takes on the attributes of the real, becoming even more real. The argument that Taussig makes is that 'fingerprinting as a modern state practice owes everything to modern colonialism' (1993: 222). However, when one looks at the development of fingerprinting one quickly comes to the conclusion that it is not just a state practice or a specifically colonial one. Chandak Sengoopta's excellent history of fingerprinting in India, Imprint of the Raj, speaks of colonialism as a process simultaneously unfolding at different scales of empire, involving state and non-state actors. One may push this further by arguing that what is at stake here is the application of biometrics for an emergent governmentality in which, to borrow from Sengoopta, 'one needed to know individuals' (2003: 47).

Despite his utopian efforts, when William Herschel retired fingerprinting was still an ad hoc security solution lacking in scientific credibility. In 1880, prompted by Faulds's letter in Nature, he wrote of his experiences and passed his notes to Darwin's cousin, the Victorian polymath, anthropologist and father of eugenics Francis Galton. ${ }^{2}$ Galton was at that time crossing the archipelago of Victorian institutions - schools, the army, hospitals, asylums and prisons - searching within the multitude of individuals for a hidden order: heritable characteristics of 'race'. In the 1870s he experimented with composite photography at the request of the Director General of Prisons. As the British prison population swelled so too did an unsystematic photographic archive, which failed to fulfil its promise of literally capturing the habitual criminal. Galton's interest was not in the individual per se but rather in identity as a marker of generic types. Working initially with Herbert Spencer, Galton began to treat a facial image as a landscape on which locational or 'register marks' could be made, thus rendering the human face as a series of points that could then be mechanically selected (see Galton 1879). However, his experiments failed to conclusively locate generic types: the ghostly composite faces were not apparitions of criminality or insanity but merely physiological averages. Nonetheless, he understood the implications of moving in the opposite statistical direction, towards personal identification. The technical literature on biometric face recognition still salutes his pioneering work on mechanical selection for composites, in particular systems using the Principal Component Analysis techniques developed by Galton's protégé Karl Pearson (see Quintiliano and Rosa 2006, Galton 1889).

Galton's interest in fingerprints, sparked by Herschel, was similarly motivated by a desire to see beyond individual differences towards heredity and 'race'. However, one of his greatest scientific contributions was indexing and classification for individual identification. Throughout

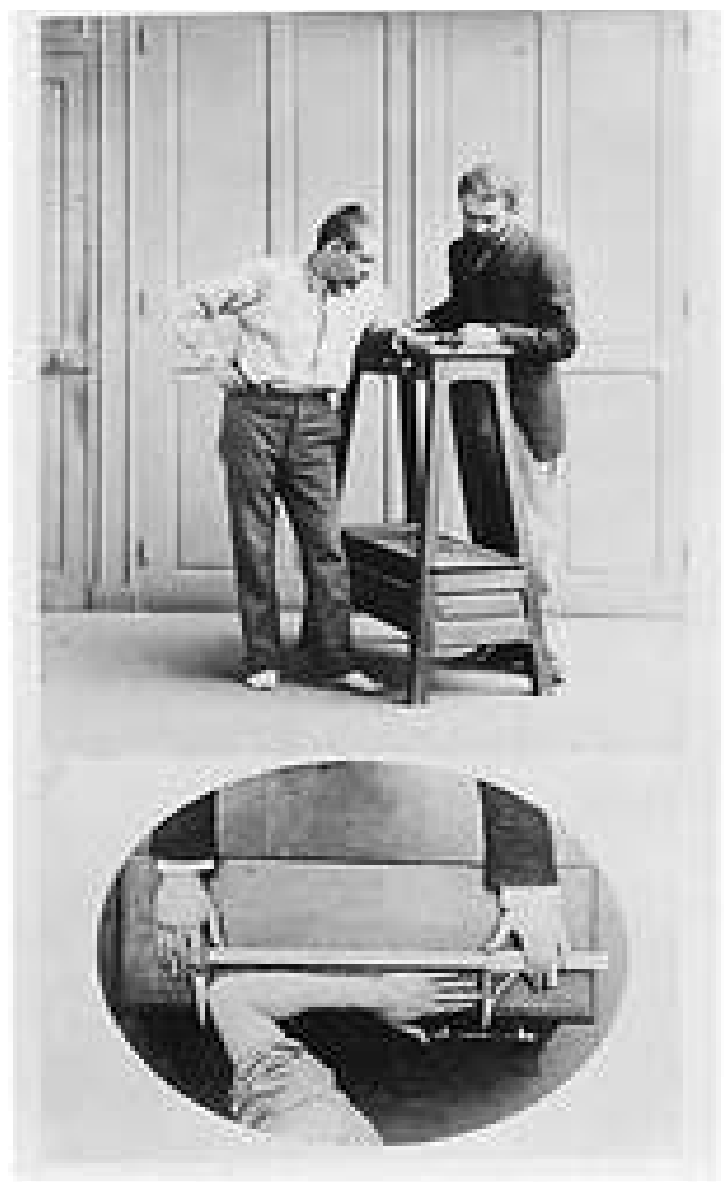



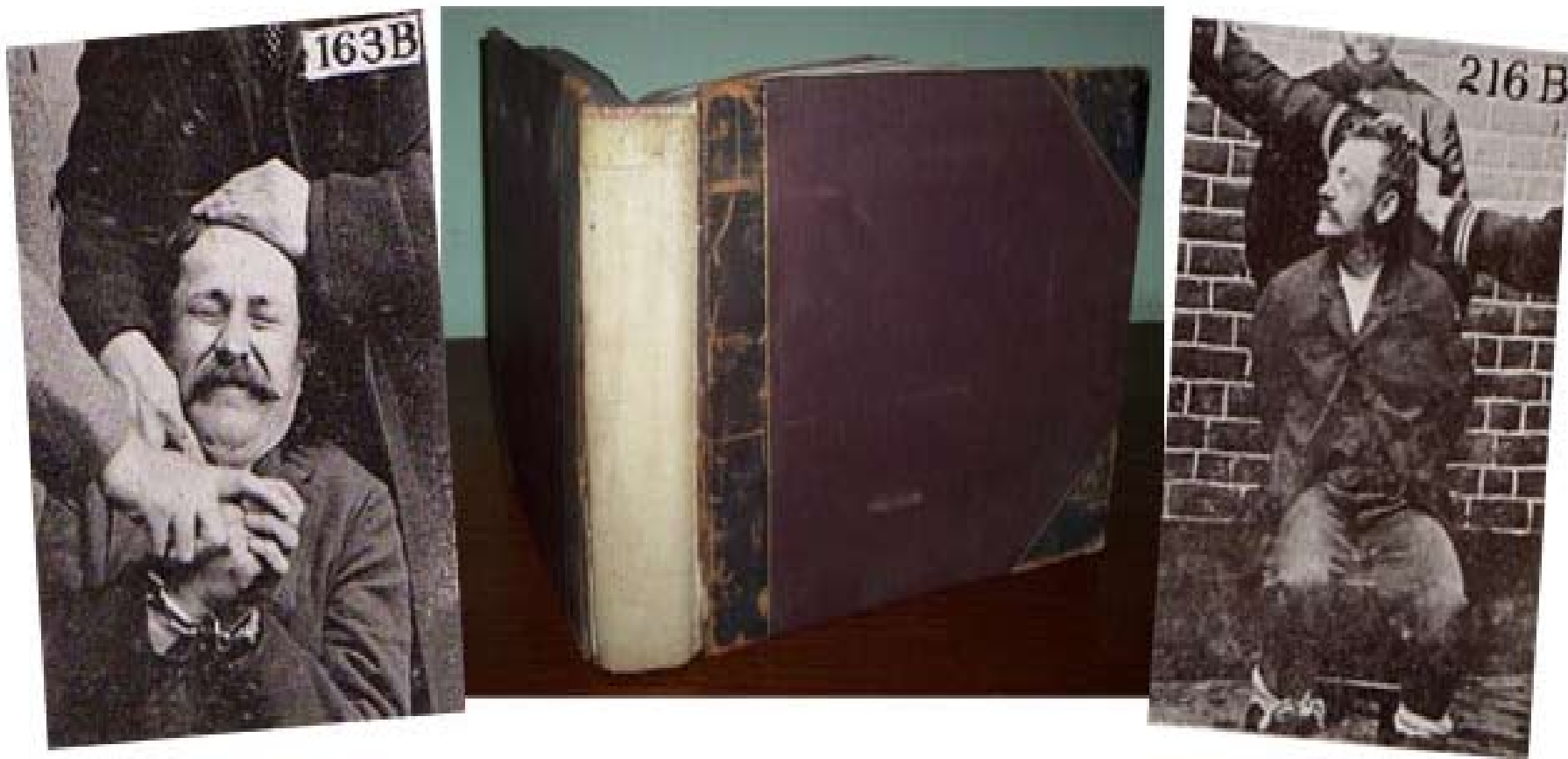

Fig. 6. An Unwilling Sitter in Pinkertons Criminal Mug Shot \& Information Book, 1895 Allen Pinkerton, like Bertillon in France, was a pioneer of standardised, description and photographic practice.

reliable of all biometrics has emerged - an unquestioned legal technology through which the criminal's prints may even be, one-to-one, scientifically 'matched' with those left at a crime scene. This image is at variance with reality, practically and theoretically. In terms of enrolment, prints may be partial or otherwise distorted. There is also the issue of scientifically verifiable standards for 'matching'. Up until 2001 the UK used a 16-point standard of similarity, and many other jurisdictions favour ridgeology. The key issue is statistical individualization, or the process used to determine a match to the exclusion of all others. Confidence levels can be attributed to either a positive or negative result only with reference to the population.

Beavan, C. 2002. Fingerprints: The origins of crime detection and the murder case that launched forensic science. London: Hyperion.

Bertillon, A. 1893.

Identification

anthropométrique:

Instructions signalétiques.

Paris: Imprimerie

Administrative.

- 1896. Signaletic instruction including the theory and practice of anthropometrical identification. Chicago, New York and London: The Werner Company.

Cole, S. 2001. Suspect identities: A history of fingerprinting and criminal identification. Cambridge, MA: Harvard University Press. the 1880 s, while operating his celebrated Anthropometric Laboratory at the International Health Exhibition in Kensington, he pushed fingerprinting along the path to scientific credibility. Though no trace of temperament or 'race' could be found in the arches, loops or whorls, Galton was keenly aware of the significance of his contribution. Habitual criminals in the vast unmapped spaces of metropolitan London, immigrants and (in his words) native 'coolies' in the furthest reaches of empire could all be securitized. Later, he imagined a role for biometric security in a eugenic utopia, and a fragment of that vision remains. Towards the end of his life, the scientific flaneur dictated a novel that was partially destroyed titled, The Eugenics College of Kantsaywhere. In the manuscript, Professor I. Donoghue arrives at a colony segregated according to genetic fitness. Enforced celibacy and labour camps await those of inferior stock, though upward mobility is possible through College examinations. The protagonist is genetically screened in a manner apparently resembling that of the Army, Indian Civil Service or a careful insurance office. The final process is to leave one's fingerprints for future identification. The Professor notes, 'All immigrants are more or less suspected' (1906: no pagination). 'I had never been so keenly looked over before,' remarks Donoghue, before explaining:

What they are concerned with in one another are the natural, and therefore the only heritable characteristics. [...] His 'brute value' would be a proper expression if employed in the original sense of that word. [...] In Kantsaywhere they think much more of the race than of the individual.

In the $1880 \mathrm{~s}$, when he was experimenting with fingerprinting and directing his anthropometric lab, Galton was compelled to investigate parallel efforts in Paris, where Alphonse Bertillon was fast achieving fame as a detective who thought much more of the individual than of the 'race'. If Galton epitomized the polymath scientist, Bertillon - not unlike William Herschel - worked on the practical and administrative side of research. Fears over crime conditioned the birth of biometric security in fin-desiècle Paris. In the 1860 s the city was 'modernized', with only 40 percent of its buildings remaining untouched by Baron Haussmann. The goal was to open streets out and allow circulation; however, for many it was the city's circulation that was the cause of its problems. Paris was now open to the 'dangerous' class of récidivistes (recidivists) - people who were mobile in identity as well as move- ment - and into this context stepped Bertillon, an obsessive police clerk.

Efforts had been made to identify recidivists through silhouettes and, later, as in Britain, crude and unsystematic photographs accompanied by unverifiable names. By 1882 Bertillon had agreement to anthropometric measurement of arrested persons. However, this could not confirm identity conclusively, so Bertillon added standardized photographs and the portrait parlé or verbal portrait. The details were then entered on cards and meticulously filed. In the years to follow, Bertillon's legacy would be composed of such visual innovations, though his key contribution was, as Allan Sekula notes, 'not the camera but the filing cabinet' (1986: 16). When one looks back at Bertillon's methods once can see a curious statistical mechanism: that of recording the body's markers, normally common to all, in sufficient detail as to render them specific to one. The exercise was essentially a working out of three problems. Firstly, Bertillon noted the problem of human vision. He argued that to see 'tall' or 'short' people is to perceive them in a meaningful way. His goal was to standardize the police gaze. Secondly, he wished to standardize the recording of physical and social traits. Seeing was also writing, a coded gaze. Thirdly, he archived the file on each subject by 'individualising him in the midst of the multitude of human beings' (1893: 4).

By 1885 Bertillonage was receiving worldwide attention and its inventor even eclipsed Sherlock Holmes as the foremost detective in Europe in Sir Arthur Conan Doyle's story, The Hound of the Baskervilles. That year, his mind on fingerprinting, Francis Galton visited Bertillon to discuss his methods and be entered into the system. Galton regarded the whole business as less of a triumph in science and more of a triumph in filing - perhaps correctly so. But Bertillon was still riding the wave of success. His publisher's introduction to the English edition of Signaletics is effusive:

[E]very human being should be partially signalised. [...] The process of signalment would take the place of passports at every frontier, and signalments would appear on all life assurance policies, permits and other papers. [...] It would then be possible to find any person at once whenever desired, whether for its own good or that of society at large, in whatever place he might be and however he might alter his appearance or his name. Crime would thus be rooted out, elections purified, immigration laws effectively enforced, innumerable misunderstandings and much injustice prevented and all business relations greatly facilitated. (1896: viii) 

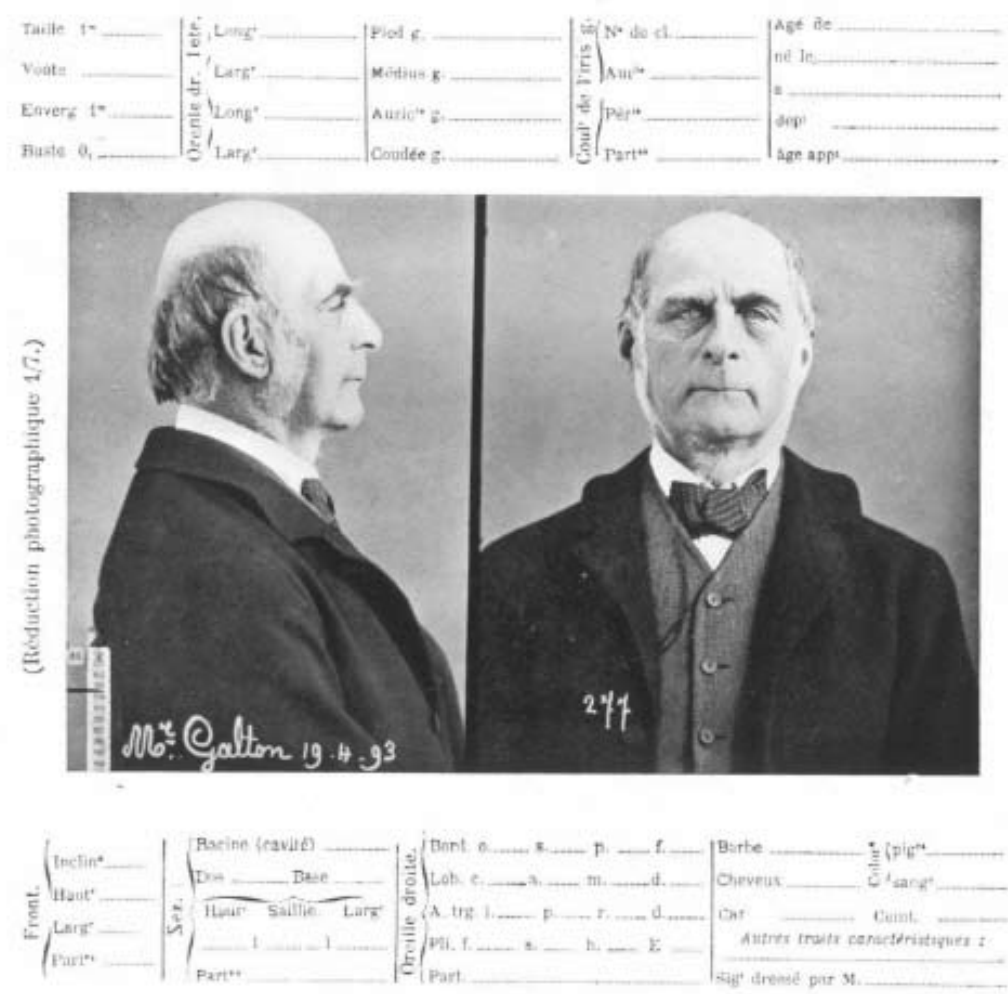

Fig. 7. Anthropometry card of Francis Galton, with profile and full-face photos and spaces for key body measurements, taken by Alphonse Bertillon, 1893 University College London, $F G, 84$

Conan Doyle, A. 1998. The hound of the Baskervilles: Another adventure of Sherlock Holmes. Oxford: Oxford University Press.

Faulds, H. 1880. On the skin-furrows of the hand. Nature 28 October: 605.

Foucault, M. 2004. Security, territory, population: Lectures at the College de France, 1977-1978. Basingstoke and New York: Palgrave Macmillan.

Galton, F. 1879. Composite portraits made by combining those of many different persons into a single figure. Journal of the Anthropological Institute 8: 132-148.

- 1889. Personal identification and description. Journal of the Anthropological Institute 18: 177-191.

- 1906. 'The Eugenic College of Kantsaywhere'. Unpublished MS, University College London, FG 138/6.

Herschel, W.J. 1880. Skin furrows of the hand. Nature 25 November: 76

Lyon, D. 2007. Surveillance studies: An overview. Cambridge: Polity Press

Maghiros, I. et al. 2005. Biometrics at the frontiers: Assessing the impact on society. European Parliament Committee on of populations through racial theories to knowledge of the individual units of those same populations; it is a history marked by scientific innovation as well as administrative and governmental deployments; however, perhaps most intriguingly, it speaks of a vision of security - a utopian excess - that pushed against the limits of 19th-century technology and acceptability.

Considering the genealogy of biometric security draws attention to security as an appropriate field of anthropological enquiry. If we follow Michel Foucault, security must be considered as a productive apparatus: it allows 'circulations to take place [...] controlling them, sifting the good from the bad, ensuring that things are always in movement [...] but in such a way that the inherent dangers of this circulation are cancelled out' (2004: 65). This insight remains underdeveloped in his work, but links individuals and their mobility to bio-political power and governmentality. Biometric security, in the 19th century as today, oscillates between knowledge of and power over populations and the securitization of individual identity.

For Francis Galton anthropometry, photographs and fingerprints held the promise of finding in a multitude of individuals, types whose heritable characteristics would illuminate evolutionary and racial thought; his statistical genius instead found individual security. But while overt racial theory no longer has a place in the literature on biometrics, so-called 'categorical suspicion' does: an individual fingerprint or face is significant because it is a unit within a population - a population enrolled in a database, a population not enrolled or denied access, potentially a suspect population. In this sense, biometrics are indexical.

A genealogy of biometrics also demands that we consider security as an assemblage of different elements operating in specific contexts. The worlds of Francis Galton's anthropometric laboratory and Alphonse Bertillon's police archive were very different; however, they both responded to contexts in which the mobility of bodies and the malleability of individual identity was rendered problematic. Both London and Paris were imperial metropolises, magnets for large-scale immigration and landscapes darkened by real and imagined criminals, marked off as different and potentially set against the polis. While Galton's mind wandered from photography to fingerprinting and anthropometry, indexing and classifying, the utopia he imagined was one ordered by heredity and supported by a system of biometric security. For Bertillon anthropometry was at the core of a utopia always just beyond his reach. Signaletics, contrary to his expectations, ultimately failed to slip its moorings in criminal identification and move into ever newer areas of civil life. As Simon Cole has convincingly argued, while Bertillon's anthropometric system was considered to be far more 'scientific' than its competitors well into the 20th century, its demise was more of a victory for 'industrial-style speed, efficiency, productivity, and economy over what was seen as scientific accuracy and precision' (2001: 93).

In practical terms, an understanding of the birth of biometric security also helps temper images of the newness of the contemporary revolution. While face recognition systems developed into their modern form through technological advances made in the 1960s, the standardized gaze of the police mug-shot, its augmentation of other security apparatuses and pioneering work on mechanical selection have a much older history. Fingerprinting, on the other hand, quickly found a place in the craft of policing, where technical experts succeeded in rendering it an objective and ostensibly sure-fire method of criminal identification emptied of socio-cultural meaning. ${ }^{3}$ 
Fig. 8. 'USA or Ireland?' The Shannon Free industrial zone is forerunner of contemporary export zones throughout the world. In order to facilitate the fast movement of US travellers in the 1960s, Shannon Airport began to operate a US Customs check-in area where one could 'technically' enter the US by pre-clearing customs. Biometric security provides another mechanism through which borders can me rendered mobile.
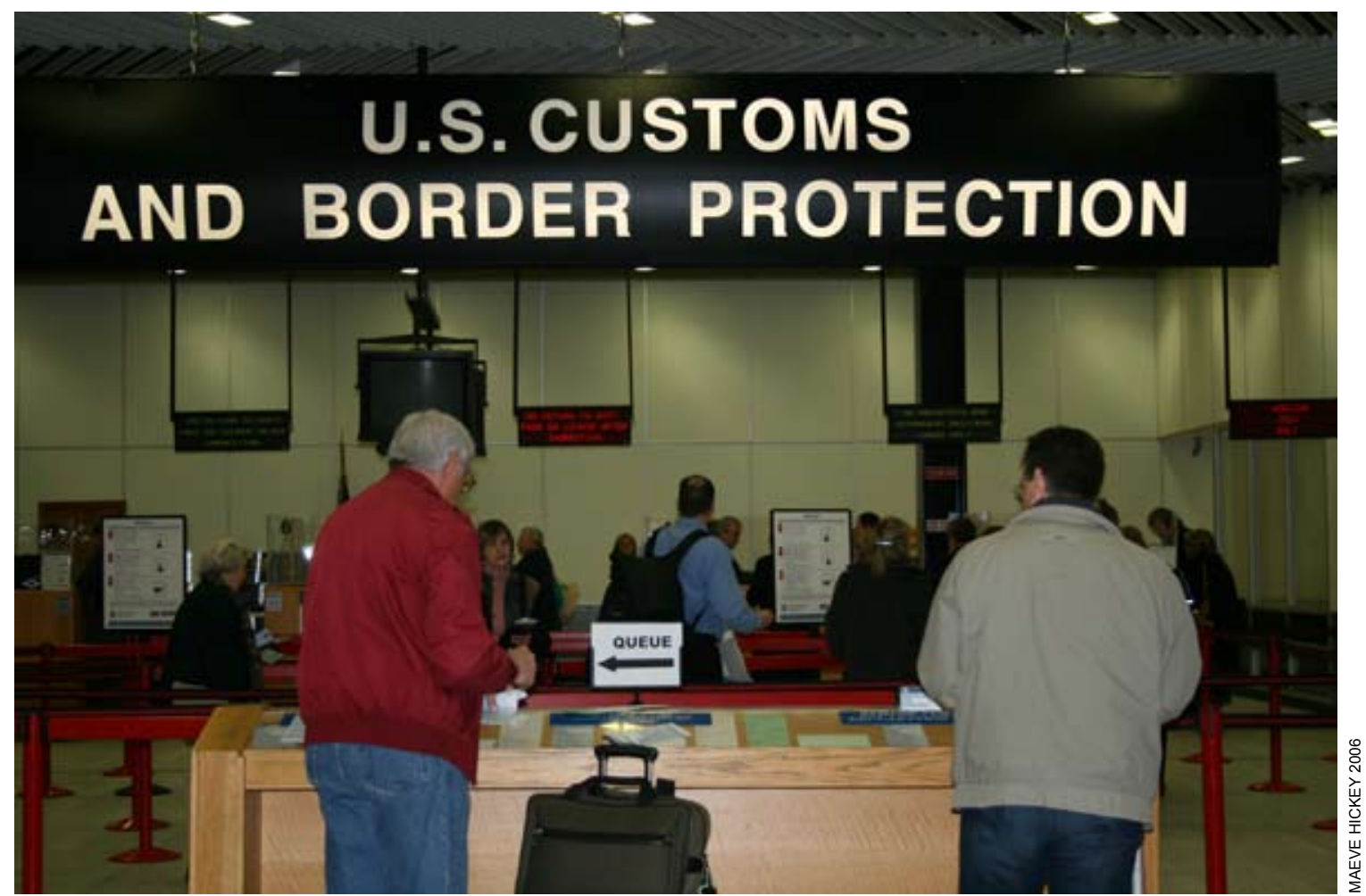

\section{Conclusions}

The past two decades has seen a revolution in biometric security. In the wake of September 11, technological applications have increasingly been promoted by public and private interests as a way to make borders 'smart', police welfare and benefit payments, promote reduced-risk financial transactions and increase surveillance on suspect populations. The rather sober-minded report of the European Parliament captures the situation well:

The diffusion of biometrics is currently led by government applications with the aim of improving public security [...] but will go far beyond these specific issues. As citizens get used to biometric identification in their dealings with border control $[\ldots]$ the association with criminal behaviour will diminish and people may be more prepare $[s i c]$ to accept the use of biometrics for other purposes as well [...] and even simply to enhance their convenience or for fun. (Maghiros et al. 2005: 115)

In a world of new applications and constant experimentation, older biometrics such as fingerprinting and face recognition sustained their central position. Since the 1980 s, technological advances have facilitated the production of high-quality devices that are relatively low in cost. For example, iris scan technology is already being piloted for bank pass machines (ATMs), and 'livescan' Automated Fingerprint Identification Systems (AFIS) are already popular with police forces throughout the world. Together with digital fingerprinting, biometric face recognition is at the heart of International Civil Aviation Organization (ICAO) guidelines, promising 'never again' to debacles such as the 2004 grounding of US Senator Ted Kennedy, because ' $T$. Kennedy' appeared on a no-fly list, or the detention of Catherine Stevens, wife of a Republican Senator and former chair of the Senate committee on airline regulation, because her name resembled the former stage name of singer Yusuf Islam - Cat Stevens. But advances in interface technologies are just one of the enabling developments. The development of databases and their capacity for speedy enrolment have allowed the utopias of the 19th century to be re-imagined, causing much disquiet. In the area of mobility control, for example, 'positive' or 'negative' enrolment will mean enhanced movement and access for some and immobility and exclusion for others.

My specific concern is with the application of biometric security for mobility control. If one is to look at areas such as border control, from the US/Canadian border to the UK's smart borders scheme, it quickly becomes obvious that biometrics offer not merely a way of enhancing the verification of identity but rather a technology that will enable the development of de-territorialized e-borders. The UK Home Office strategy, Controlling our borders, for example, makes it clear that biometrics will be at the centre of electronic systems designed to deter or remove some persons, while allowing 'fast and secure automated clearance $[. .$.$] for certain categories of regular travellers'$ (2005: 34). Moreover, the border may well begin with data enrolment at a point distant from the UK. If one takes such changes to mobility into account alongside the uses of biometrics in other civil areas then anthropological attention to a developing assemblage of graduated biometric citizenship takes on a new urgency.

Perhaps the most important conclusion arising from a survey of the 19th-century 'discovery' of the capacities of biometric nature copies is the simplicity of the governmental issue at the core of their deployment. A contemporary example from the conflict in Iraq illustrates this perfectly. From the start of the so-called insurgency, US personnel reported a significant operational difficulty in carrying out security duties: they were provided with the names of 'bad guys', old and sometimes photocopied photographs and vague written descriptions - black hair and a moustache was an inadequate description in a milieu in which soldiers reported an inability to tell people apart. Nowhere was this problem more acute than in Fallujah. The solution offered was bio-governmental. According to Lieutenant Colonel Jeff Smitherman, the city was electronically walled off: 'Like Mao said, insurgents are like fish swimming in the sea of the people' and biometric nets would 'keep 'em from swimming freely' (Shachtman 2007: 1). Anthropology is uniquely placed to see beyond public discourse on the efficacy of new technologies and instead draw attention to the historical and cultural dimensions of biometrics, to see connections between deployments in the Western world and in more distant 'laboratories', and to develop research on emergent configurations and assemblages. Here I have attempted to explore the genealogy of biometric security - an invisible chain that held past populations in strikingly contemporary ways. $\bullet$ 
